\title{
La victimización entre iguales y la adaptación psicosocial: experiencias de la juventud inmigrante canadiense
}

\author{
${ }^{1}$ Departamento de Psicología, York University, \\ Toronto, Ontario \\ 2 Departamento de Psicología, York University y el Hospital for Sick Children, \\ Toronto, Ontario \\ ${ }^{3}$ Departamento de Psicología, Queen's University, \\ Kingston, Ontario
}

\section{Canadá}

pepler@yorku.ca 


\section{Resumen}

Este trabajo explora las experiencias de victimización entre los jóvenes inmigrantes en Canadá. Más concretamente, su implicación en la victimización general y étnica -ser víctima de abusos debido al color, raza, etnia- se examinó utilizando una muestra de alumnos de Educación Primaria y Secundaria de diferente etnias. No hubo diferencias significativas en la prevalencia de victimización general entre los grupos de inmigrantes. Se encontró una tendencia entre el hecho de ser inmigrante y ser víctima por razones étnicas, de forma que los jóvenes nacidos en Canadá, pero cuyos padres nacieron fuera (canadienses de primera generación), eran los más afectados. En cuanto a su adaptación, el estatus de inmigrante no moderaba la asociación entre victimización étnica y la interiorización/exteriorización de problemas. Sin embargo, los jóvenes que informaron sufrir malos tratos a causa de su origen étnico señalaron tasas altas de incidencia tanto en ese momento como un año después. Por último, se presentan implicaciones para la intervención temprana de la victimización étnica, al igual que las limitaciones del estudio y orientaciones para futuras investigaciones.

Palabras clave: victimización iguales, etnicidad, inmigración, juventud, jóvenes, adaptación psicosocial 


\section{Introduction}

After twenty years of research on bullying and victimization among children and youth, it is now widely accepted that these experiences are pervasive and represent frequent, if not daily, occurrences, for a significant number of youth. A great deal of empirical study has been directed towards understanding the risks and protective factors associated with victimization, the manifestation of this behaviour, as well as the negative consequences associated with such experiences. It is only recently that the literature has begun to move towards understanding the experience of peer victimization among specific subgroups of children, particularly groups of marginalized youth (e.g., Williams, Connolly, Pepler, \& Craig, 2005). In line with this growing trend, the current study aims to examine the peer victimization experiences of an often neglected subgroup of youth: immigrant youth.

Bullying has recently been conceptualized as a relationship problem, as this form of aggressive behaviour unfolds in the context of a relationship between peers (Pepler \& Craig, 2000). This aggression can be exhibited through negative physical, verbal, or social activities that are designed to cause distress to victimized children (Olweus, 1991). With repeated episodes of bullying, the power differential that exists between the child who bullies and the child who is victimized becomes consolidated, such that the child who is being bullied becomes increasingly powerless to defend himself (Craig \& Pepler, 2003). As a result, these children are frequently unable to extract themselves from a bullying relationship because they lack the power to shift the dynamics necessary to put a stop to this abusive behaviour. Children who are involved in these types of destructive interactions are learning about power in relationships. Children who bully are learning how to use their power aggressively to control and cause distress to others, whereas children who are victimized are learning about helplessness in the experience of being dominated in an abusive relationship (Pepler \& Craig, in press).

Children who bully generate their power over others through their physical stature, age, gender, popularity, or awareness of another's vulnerability. Within our society, there is also systemic power based on discrepancies among certain groups. This marginalization can be based on sexual orientation, economic status, disability, and racial or cultural background. Therefore, some youth may feel entitled to exert power over others because of their membership within a social or cultural context. Youth who live in their country of origin may assert 
their sense of belonging to the prevailing cultural group as a means of creating a power imbalance with youth from immigrant families. Bullying that targets another's ethnic background or cultural identity in any way is referred to as ethnic bullying. This form of bullying may include direct forms of aggression such as racial taunts and slurs, derogatory references to culturally-specific customs, foods, and costumes, as well as indirect forms of aggression, such as exclusion from a mainstream group of peers because of ethnic differences.

There are many anecdotal reports of the pervasiveness of ethnic bullying among youth. For example, Besag (1989) reported that in one group of 13- to 17-years olds, over half the name-calling that occurred referred to racist names and that over 60 different abusive racial terms were used. A recent study of Dutch youth revealed that one out of five youth of an ethnic Dutch background reported having experienced racist name-calling whereas one out of three ethnic minority youth living in Holland reported experiencing this same form of ethnic bullying (Verkuyten \& Thijs, 2002). Very few studies have extended this examination to the victimization experiences of immigrant youth. One of the few studies to examine this topic was conducted by $\mathrm{Yu}$ and her colleagues (2003) through an analysis of the American data from the World Health Organization Study of Health Behavior in School Children. Using data from youth in grades 6-10, the authors used language spoken at home as a proxy measure of immigration status and acculturation. Their results suggest that youth who did not speak English at home (i.e., had a lower level of acculturation) were 2.0 to 4.5 times more likely to be bullied because of their race or religion than were youth who only spoke English at home. The results of two more recent studies explore the association between immigration and peer difficulties, although peer victimization was not specifically examined. The first of these studies explored immigrant youth in Israel and revealed that second generation youth (i.e., adolescents born in Israel to parents who emigrated from Russia) reported fewer problems with peers than did adolescents who had, themselves, immigrated to Israel (Slonim-Nevo, Sharaga, Mirsky, Petrovsky, \& Borodenko, 2006).The second study examined immigrant youth in Norway and found that second generation youth reported significantly fewer peer problems than first generation youth, with second generation girls reporting the fewest difficulties (Oppendal, Røysamb, \& Heyerdahl, 2005).

To our knowledge, there are few, if any, studies that have examined peer victimization among immigrant youth in Canada. Such an examination would be highly relevant, given the significant proportion of Canadian society that is composed of foreign-born individuals. 
According to Statistics Canada (2003), as of May 2001, 18.4\% of the total population or 5.4 million people were born outside of the country. Moreover, of the 1.8 million immigrants who arrived during the 1990s, 17\% were school children aged between five and sixteen. Now, nearly one in five school-aged children living in Toronto, the city in which this study was conducted, had immigrated within the past 10 years. Given that recent census data indicate more than 200 different ethnic origins within the country, the peer groups of school-aged children in Canada comprise youth of diverse racial, cultural, and immigration backgrounds.

Although there has been little work to date on the ethnic victimization experiences of Canadian youth, the prevalence of general victimization has been well-established. Data from the World Health Organization Health and Behaviour Survey of School-Aged Children (HBSC) indicated that Canada ranked $27^{\text {th }}$ out of 35 countries on measures of peer victimization. More specifically, $17 \%$ of Canadian boys and 18\% of girls between 11 and 15 years of age report having been bullied at least twice in the last 5 days (Craig \& Harel, 2004). The high proportions of Canadian students who report being bullied confirm that this is an important social problem both for current relationships of children and youth, as well as for the future social fabric of Canada. The prevalence of general victimization, combined with the diversity of Canadian society, may facilitate power imbalances based on identification with a cultural group that lay the foundation for ethnic bullying and the marginalization of immigrant youth. Given the prevalence of general victimization among Canadian youth and the expected power differential that may exist between native-born and immigrant youth, it was expected that immigrant youth would report greater general victimization as well as greater ethnic victimization than would non-immigrant youth.

There is now a general consensus among researchers that being victimized by one's peers is associated with a range of negative psychosocial consequences. For example, Juvonen and Graham (2001) found that youth who are bullied by their peers frequently experience loneliness, low self-esteem, depression, and social anxiety. Not surprisingly, youth who are bullied tend to have an aversion to the school environment. As early as kindergarten, children who are nominated as victims by their peers in sociometrics ratings are more likely to report that they dislike school (Kochenderfer \& Ladd, 1996). This finding extends to older youth as well (Rigby \& Slee, 1993). The negative consequences also extend to physical health. Rigby (1998) found that high school students who reported being bullied at least once 
per week tended to report more physical symptoms, such as headaches, mouthsores, and "thumping" in the chest.

In contrast, we know very little about the consequences of being victimized because of one's ethnic background or cultural identity. The results of several studies on experiences of discrimination among immigrant groups suggest that ethnic bullying may be associated with similar negative maladjustment. For example, Stevens, Vollebergh, Pels, and Crijnen found that the perceived discrimination of Moroccan adolescent immigrants in the Netherlands was associated with greater internalizing (2005b) and greater externalizing (2005a) difficulties. As well, first generation Norwegian youth reported greater perceived discrimination than did native born youth and discrimination was a significant predictor of conduct problems, emotional difficulties, hyperactive behaviour, and peer problems (Oppendal, Røysamb, \& Heyerdahl, 2005). The results from this selection of studies suggest that immigration status may serve as a moderator of adolescents' psychosocial adjustment associated with ethnic victimization. In other words, the association between peer victimization and psychosocial difficulties may be stronger for immigrant youth compared to non-immigrant youth.

Despite the limited research on ethnic victimization and immigrant youth, the literature on adolescent identity development suggest that assaults to one's sense of self and one's group affiliation may be detrimental to adjustment. In adolescence, youth are beginning the process of developing their social identity, which is the part of the self that derives from memberships in social groups (Ashmore, Deaux \& McLaughlin-Volpe, 2004). One aspect of this social identity that is salient for adolescents, particularly for youth from minority ethnic groups, is their identification with their ethnic or cultural background (Fuligni, Witkow, \& Garcia, 2005). Adolescents begin to develop this sense of identity by affiliating with others who are similar to themselves (Hamm, 2000). For many youth, this similarity could be based on race, ethnicity, or immigration status, such that native born youth associate primarily with youth who were also born in the host country and youth born outside of the country may affiliate primarily with members of their own ethnic groups. Such affiliations create visible distinctions between individuals who are considered part of one's group and individuals who are not part of one's group. Youth who were born outside of a host country may be at risk for victimization, as they are perceived as different from, less central and perhaps less entitled than youth who were born within the country. In line with this idea, the empirical work of Nesdale and his colleagues (Nesdale, Durkin, Maass, \& Griffiths, 2004) has revealed that 
young children prefer to be members of high status groups rather than low status groups. Moreover, out-groups of children are liked less when they comprise children from different ethnic backgrounds compared to children of the same ethnicity as the in-group (Nesdale, Maass, Griffiths, \& Durkin, 2003). In a diverse society with many tangible reminders of immigration status (e.g., ethnic background, language, dress, etc.), immigrant youth may be at a greater risk for being bullied because of their ethnic background compared to youth born within the host country.

Given that immigrant adolescents face additional challenges to the development of their sense of identity, experiencing ethnic victimization may be more detrimental to their psychosocial adjustment compared to nonimmigrant youth. The experience of immigration or being the children of immigrant parents ensures that development of ethnic identity is made more complex by the process of acculturation and intergenerational conflict (Rumbaut, 1996). Youth must decide if they will maintain an ethnic identity consistent with their parents' country of origin or assume the identity, practices, and culture of their adoptive country. Youth likely experience a great deal of tension as a result of trying to balance their family's traditions and those of their new host culture. Given the salience of identity during this stage of adolescence and the additional challenges immigrant youth experience, peer victimization that is focused on sensitivities regarding ethnic identity may be particularly detrimental to immigrant youth. As such, it was expected that immigrant youth who were bullied because of their ethnic background would report greater internalizing and externalizing problems both concurrently and over a one year period than would non-immigrant youth.

In sum, the present study examined the prevalence of general victimization and ethnic victimization among immigrant and non-immigrant Canadian youth. As well, immigration status was explored as a moderator of victimization experiences to determine whether immigrant youth were at a higher risk for negative psychosocial adjustment as a result of such negative peer interactions compared to non-immigrant youth. 


\section{Method}

\section{Participants}

Data for these analyses were drawn from a larger longitudinal study of adolescents' antisocial behaviour, including bullying and victimization, psychosocial adjustment, and relationships with parents and peers. The sample for the current study comprised students recruited from three elementary schools and two high schools to obtain a sample that was relatively representative of the socioeconomic and ethnic diversity of the major Canadian city in which the study was conducted. All students in grades 7 through 11 were invited to participate; however, only those students and their parents who provided written consent were allowed to complete the study $(\mathrm{N}=506)$. As such, 198 elementary school students and 308 high school students consented to participate in the research. Female students comprised the majority of the sample $(61.9 \%)$ and the mean age of participants was 13.94 years $(S D=1.02)$. The majority of the students identified themselves as European-Canadian (74.9\%). The remainder of the sample was ethnically diverse: 9.9\% Asian-Canadian, 3.8\% African/Caribbean-Canadian, 3.8\% South Asian-Canadian, 1.4\% Latin American Canadian, 1.0\% Middle Eastern Canadian, and 5.3\% Other Ethnicities. Immigration status was based on the country of birth of participants and their parents. Youth who were born outside of Canada were classified as $0^{\text {th }}$ generation $(21.1 \%)$; whereas youth who were born within Canada, but whose parents were born elsewhere, were classified as $1^{\text {st }}$ generation (20.6\%). Participants who reported that both they and their parents were born within Canada represented the majority of the sample $(58.3 \%)$ and were classified as $2^{\text {nd }}$ generation. Chi square analyses were conducted to evaluate the association between ethnicity and immigration status. The results suggest that there was significant overlap between these constructs, $\chi^{2}=118.84, p<.001$, such that youth who identified themselves as European Canadian were overrepresented in the $2^{\text {nd }}$ generation classification. Youth who identified themselves as an ethnic minority (i.e., any ethnic group other than European-Canadian) were overrepresented in the $1^{\text {st }}$ generation classification. The mean number of years that $0^{\text {th }}$ generation youth had lived in Canada was 7.22 years $(S D=4.05)$. Fifty percent of $0^{\text {th }}$ generation youth mostly or only speak English at home, compared to $82.7 \%$ of $1^{\text {st }}$ generation youth and $97.6 \%$ of $2^{\text {nd }}$ generation youth. The parents' highest level of educational achievement was used as a proxy measure of socio-economic status. Almost half of the adolescents reported that their mothers (45.1\%) and fathers $(43.9 \%)$ had obtained at least some post-secondary education, which suggests that this sample was fairly well- 
educated and advantaged. The majority of participants in this study also came from twoparent families, with $71.3 \%$ students living with both biological parents.

\section{Instruments}

Victimization. A modified Bully/Victim Questionnaire (Olweus, 1989) derived general victimization scores from two items, "About how many times have you been bullied in the last five days at school?" and "How often have you been bullied at school since the beginning of the school year?" To assist students' comprehension of bullying and victimization experiences, a brief description of bullying was provided with examples of bullying behaviours. Participants responded on a five-point scale, with '0' meaning "never" and '4' representing "several times per week". The mean of the sum of these two items was used to obtain an overall score of general victimization. The internal reliability of the total victimization score was .83. To obtain a measure of ethnic victimization, students responded to an additional question, "Have you been bullied by a student from another ethnic group because of your ethnicity?" Students responded on a similar five-point scale, with '0' representing "never" and '4' meaning "several times per week". Participants completed the victimization questions at the first wave of data collection.

Adjustment. A shortened Youth Self-Report (YSR; Achenbach, 1991) assessed both internalizing and externalizing behaviour problems. Participants were asked to rate the occurrence of problems in the preceding 6 months on a three-point scale ranging from ' 0 ' representing "Not true" to '2' meaning "Very true or often true". The internalizing score is determined by the sum of scores on items in the Somatic Complaints, Anxious/Depressed, and Withdrawn syndrome scales. The externalizing score is indicated by the sum of scores on the Delinquent and Aggressive behavior scales. Thirty items comprised the internalizing scale and thirty-two items represented the externalizing scale, both of which had adequate internal reliability (.91 and .86 , respectively). Participants completed this measure at both waves of the data collection.

Skewness of measures. Of note, the distributions for all the variables were somewhat positively skewed, ranging from 1.02 for internalizing problems at Time 1 to 3.99 for ethnic victimization. Although such skewness indicates that the majority of the students were faring well with few if any difficulties with victimization and fairly positive adjustment, such depar- 
tures from normality are problematic for statistical analyses. We transformed the variables by taking the natural logarithms; the analyses using the transformed variables yielded results similar to those with untransformed data. For ease of interpretation, our analyses involving these measures have been conducted with the untransformed data.

\section{Procedure}

Trained research assistants and graduate students administered the self-report questionnaires to the students during regularly scheduled class time. Adolescents completed the surveys in the spring of each academic year over a two-year period. Students were informed of the voluntary and confidential nature of the study and participants and/or the school were compensated for their time with a small honorarium.

\section{Results}

As there were no significant differences on the dependent variables across age and school contexts, the data were aggregated and the elementary school and. high school data were analyzed together. To identify the proportion of the sample that reported victimization, the general and ethnic victimization variables were first dichotomized to reflect either no experiences or at least one incident of victimization over the past two months. A series of chisquare analyses was performed to explore differences in proportions of victimization experiences among the immigration status groups, the results of which are presented in Figure 1. There were no significant differences among the groups in terms of general victimization or ethnic victimization. Overall, $7.5 \%$ of the sample reported experiencing at least one incident of general victimization whereas $14.2 \%$ of participants reported being victimized by a student of another ethnicity because of their ethnic background at least once over the past two months.

Although there were no differences in the proportions of youth who report victimization among the immigration status groups, we decided to explore mean differences in the prevalence of victimization among the groups. Although boys and girls tend to report similar rates of victimization (Craig \& Pepler, 2003), we included gender in these analyses to explore potential differences between boys and girls in ethnic bullying experiences, given that boys tend to report more racist bullying than girls (Verkuyten \& Thijs, 2002). We conducted a series of 2 X 3 analyses of variance (ANOVAs) to evaluate the effects of gender and immigra- 
tion status on general victimization and ethnic victimization at Time 1 . The means and standard deviations for all variables included in subsequent analyses are presented in Table 1 and the results of the ANOVAs are presented in Tables 2 and 3. Contrary to expectations, there was no main effect of immigration status for general victimization. There was, however, a small yet significant main effect of gender, $F(1,499)=5.91, p=.02, \eta^{2}=.01$, such that boys reported greater general victimization than did girls. Using ethnic victimization as the dependent variable revealed a different pattern of results. There was a marginally significant main effect of immigration status, $F(1,499)=2.53, p=.08, \eta^{2}=.01$. Given the exploratory nature of this study, pairwise comparisons were conducted even though the effect did not reach statistical significance. Using Tukey HSD procedures to control for Type 1 error across the comparisons, a trend emerged for a difference between $1^{\text {st }}$ and $2^{\text {nd }}$ generation youth, such that $1^{\text {st }}$ generation youth reported higher rates of ethnic victimization. The results of the comparisons are presented in Figure 2. The results also suggest a significant main effect of gen$\operatorname{der}, F(1,499)=7.19, p=.01, \eta^{2}=.01$, with boys reporting greater ethnic victimization than girls.

To examine immigration status as a moderator of ethnic victimization and negative psychosocial adjustment, both concurrently and one year later, a series of hierarchical regression analyses was conducted. The intercorrelations between the variables are presented separately for each immigrant status group in Table 5. We entered gender and immigration status in the first step of the regression model to examine the effect of demographic information on adjustment. Immigration status was dummy coded with $2^{\text {nd }}$ generation status as the reference group. As such, the $1^{\text {st }}$ generation status group was compared to the $2^{\text {nd }}$ generation group, which was followed by a comparison of the $0^{\text {th }}$ generation status group to the $2^{\text {nd }}$ generation group. Given the significant overall correlation between general victimization and ethnic victimization $(r=.20, p<.01)$, we wanted to determine whether ethnic victimization contributed to negative adjustment over and above general victimization. As such, general victimization was entered in step 2 and ethnic victimization was entered in step 3. We included several interaction terms in step 4 to examine the moderating effects of immigration status (Immigration $\times$ Ethnic Victimization, Immigration $\times$ General Victimization) and the moderating effects of gender (Gender $\times$ Immigration, Gender $\times$ Ethnic Victimization, Gender $\times$ General Victimization). These interactions, however, did not significantly contribute to the fit of the models and were subsequently dropped. As such, we can conclude that immigration status 
does not moderate the association between victimization and negative psychosocial adjustment.

The results of the regression analyses predicting internalizing difficulties, both concurrently and one year later, are presented in Table 5. For concurrent internalizing difficulties, the demographics included in step 1 accounted for a small yet significant proportion of the variance in adjustment (6\%). Gender differences appear to account for this effect, with girls reporting higher levels of internalizing difficulties than boys. Immigration status did not make a significant contribution to the dependent variable. After controlling for the demographics, general victimization accounted for an additional $5 \%$ of the variance in internalizing problems, such that greater reports of general victimization were associated with greater concurrent anxious, depressed, and withdrawn symptomatology. Inclusion of ethnic victimization in step 3 produces a statistically significant, but small, increase in the variance explained (1\%). These results suggest that above and beyond the effects of gender, immigration status, and general victimization, being victimized because of your ethnic identity is associated with somewhat greater internalizing difficulties. A similar pattern of results was found when this model was used to predict internalizing difficulties one year later, suggesting that the negative consequences associated with ethnic victimization are pervasive and stable over time.

The model was then applied to self-reports of concurrent externalizing difficulties, the results of which are presented in Table 6. Unlike internalizing problems, neither gender nor immigration status contributed to the variance in aggressive or delinquent behaviour. Adding general victimization to the model made a small yet significant contribution (1\%) to the model, such that being victimized was associated with higher reports of acting out behaviours. After controlling for the effects of general victimization, the addition of ethnic victimization explained a small yet statistically significant proportion of the variance in concurrent externalizing problems $(2 \%)$, such that being bullied because of one's ethnic background was associated with higher reports of aggressive and/or delinquent behaviours. Like internalizing difficulties, the same pattern of results was found when this regression model was applied to externalizing problems one year later. After controlling for demographics and general victimization, ethnic victimization accounted for $3 \%$ of the variance in externalizing difficulties one year later, again demonstrating the stability of the negative psychosocial consequences associated with this specific form of peer victimization. 


\section{Discussion}

In this study we explored the victimization experiences of immigrant youth in Cana$\mathrm{da}$, an area of research that has received little if any empirical attention to date. We wanted to examine not only their reports of general victimization, but also their experiences of being victimized by youth from different cultural backgrounds because of their ethnic identity. We had hypothesized that the socially constructed power differential that exists between groups who are part of the dominant culture and those that are not may place immigrant youth at a higher risk for both general and ethnic victimization. Moreover, given the additional difficulties immigrant youth must cope with in negotiating their sense of identity, youth who are bullied because of their ethnic identity may be at an elevated risk for negative psychosocial consequences.

Our study found partial support for our hypotheses. Although we had anticipated that immigrant youth would report higher rates of general victimization compared to nonimmigrant youth, our results suggest no differences in the prevalence of these behaviours. Such findings are consistent with the work of Strohmeier and her colleagues (Strohmeier \& Spiel, 2003; Strohmeier, Atria \& Spiel, 2005) who concluded, over a series of six independent studies, that immigrant youth in Austria were not at an elevated risk for general victimization compared to native-born youth. As well, Verkuyten and Thijs (2000) reported few differences in the overall rate of bullying among Dutch primary school children, regardless of ethnic background. We did find preliminary evidence, however, that immigrant youth were at a higher risk for ethnic victimization. More specifically, youth who were born in Canada but whose parents were born outside of the country reported the highest rate of ethnic victimization. One possible explanation for this tentative finding is that 1st generation youth may experience the greatest conflict between retaining the original cultural identities of their families and adopting an identity that is more consistent with the Canadian peer culture in which they are embedded. Their experiences of growing up within an immigrant family may place them in a gap between two worlds where they are less likely to be accepted by native-born youth and also less likely to be accepted by youth who recently immigrated into the country. In a sense, they are suspended between the old world of their family and the new world of their peer group. For some immigrant youth, this tenuous position may place them at risk for being marginalized by peers. 
Although we had anticipated that immigration status would moderate the association between victimization and psychosocial adjustment, our results suggest that internalizing and externalizing difficulties associated with victimization are unrelated to the immigration status of adolescents. Of note, these analyses were replicated using ethnic status (majority vs. minority) and we found that ethnic status did moderate the association between ethnic victimization and maladjustment (Pepler, McKenney, Craig, \& Connolly, 2006). One explanation for this discrepancy may have to do with the availability of information regarding immigration status. It is possible that peers are unaware as to whether youth were born within Canada or in another country. Ethnicity, however, is a much more salient and visible characteristic. This difference in the salience of group distinctions may explain why ethnic identity moderates the impact of ethnic bullying whereas immigration status does not.

Our analyses for the current study, however, did reveal a stable and negative association between ethnic victimization and maladjustment, regardless of immigration status. Previous work has established a positive association between general victimization and psychosocial difficulties (Hawker \& Boulton, 2000). By controlling for the association between general victimization and internalizing and externalizing difficulties, we were able to generate support for our hypothesis that ethnic victimization, although a related construct, contributes unique and significant variance to youths' reports of anxious, depressed, and withdrawn symptoms, as well as to their reports of aggressive and delinquent behaviours. The fact that this effect exists both within time and over time offers additional support for our argument that ethnic victimization has a negative impact on youths' adjustment and should be addressed by school systems.

One question that remains is the mechanism through which ethnic victimization exerts its influence on adolescents' adjustment. The answer to this question likely lies within the meaning that youth make of their victimization experiences. We know that individuals who have an affiliation with their own cultural or ethnic group are more likely to label a negative interaction as "discrimination" or racially motivated when the circumstances of the interaction, such as motivation, are unclear (Operario \& Fiske, 2001). It follows, then, that the salience of ethnicity and immigration status for some youth may predispose them to attribute their victimization to their ethnic background when, in fact, their victimization may be unrelated to this aspect of their identity. Self-reports of ethnic victimization are based on youths' 
perceptions of the motivations behind their victimization and are, therefore, highly subjective. For those youth who do attribute their victimization to their cultural identity, they are making salient, yet potentially detrimental, self-blaming attributions about themselves. Attributing victimization to one's ethnic identity suggests that victimization has something to do with inadequacies in the self (internal), that the victimization will never end (stable), and that there is nothing one can do to change it (uncontrollable). Graham and Juvonen (1998) found that youth who attributed their harassment experiences to internal features and who believed their experiences were stable and uncontrollable were more likely to exhibit poor adjustment, such as low self-esteem and loneliness. It follows, then, that attributing victimization to one's ethnic identity, a characteristic that is internal, stable, and uncontrollable, would also result in similar negative adjustment. The fact that ethnic victimization also predicts aggressive and delinquent behaviour suggests that some youth may develop externalizing coping mechanisms to manage the negative emotions associated with peer victimization based on their cultural background. Such a finding is consistent with previous research which has demonstrated that being victimized by peers places one at an increased risk for adjustment difficulties, including externalizing behaviour problems (Hanish \& Guerra, 2002).

Although this study represents a preliminary examination of the peer victimization experiences of immigrant youth in Canada, there are several limitations to the study that should be acknowledged, as they speak to the generalizability of the results. As previously indicated, the students involved in this study were relatively advantaged and most came from stable family environments. As such, their experiences may be significantly different than students from less advantaged socioeconomic backgrounds. The generalizability of these results may also be limited by the school contexts from which the samples were drawn. Immigrant youth in this study represented approximately $42 \%$ of the study population $\left(0^{\text {th }}\right.$ generation $=21 \%$ and $1^{\text {st }}$ generation $=21 \%$ ). Immigrant youth might report different experiences with ethnic victimization if they attend schools in which they represented a higher or lower proportion of the student body. If immigrant youth comprises the majority of the school population, their membership in the numeric majority may shape their peer experiences. There is some research to support the suggestion that the ethnic composition of the school has an influence on victimization experiences. Hanish and Guerra (2000) found that White children were at significantly greater risk of being victimized in predominantly non-White schools. As well, Graham and Juvonen (2002) and Verkuyten and Thijs (2002) found that youth from cultural/racial groups who were in the numerical minority were more likely to nominate mem- 
bers from these same groups as victims of peer harassment, even if such groups represent the overall majority culture in society.

Although this study has provided evidence for the prevalence of ethnic victimization among immigrant youth, we have little understanding of how immigrant youth experience this particular form of victimization. For example, are they bullied through racial slurs, physical aggression and intimidation, or social ostracism by native-born youth? Given that namecalling and social exclusion are the most common forms of bullying (e.g., Smith \& Shu, 2000), one can assume that ethnic bullying involves similar behaviour. Further work, however, is needed to answer this question. We also do not have a strong understanding of the circumstances surrounding the immigration experiences and stresses associated with immigration, nor do we know how long the parents of $1^{\text {st }}$ generation youth have lived in Canada. Additional information regarding these topics may help to elucidate possible confounding variables.

Finally, given the ethnic diversity of our sample, we chose to collapse across ethnic groups and countries of origin to obtain categories of $0^{\text {th }}$ and $1^{\text {st }}$ generation youth that were large enough for our statistical analyses. We were cognizant that doing this approach may have eliminated important distinctions and experiences between immigrant groups. For example, youth who emigrated from a similar culture, such as the U.K., may report different experiences with ethnic victimization in Canada than youth who emigrated from a distinct culture, such as China. Future studies of samples with larger proportions of immigrant youth are necessary to fully elucidate the experiences of victimization among different immigrant groups.

Despite these limitations, the results have several implications for managing ethnic bullying among youth. Although there appear to be few differences in general victimization among immigrant groups, there is preliminary evidence that $1^{\text {st }}$ generation youth may be at the highest risk for ethnic victimization. As such, teachers and parents may need to be particularly sensitive to the peer experiences of this group of adolescents and be vigilant for signs of ethnic victimization. This study also suggests that ethnic victimization, regardless of immigration group status is associated with stable psychosocial difficulties in terms of internalizing symptoms and externalizing behaviours, over and above the effects of general victimization. Adults can help to ameliorate the effects of this form of peer harassment by being 
cognizant of the negative outcomes associated with this behaviour and intervening when they become aware of such negative peer interactions. Such a suggestion is informed by the work of Verkuyten and Thijs (2002) who found that, regardless of ethnicity, fewer children reported experiences with racist bullying when they believed they could tell their teacher about it and that the teacher would react. Teachers' willingness to take a stand to protect vulnerable students may give a strong message about inclusion and acceptance within the classroom context.

Although all forms of peer victimization are injurious to youth, this study suggests that being bullied because of your ethnic identity may be particularly detrimental in terms of anxious, depressed, and withdrawn symptoms, as well as aggressive and delinquent behaviour. Intuitively, such a finding makes sense, as ethnic victimization involves not just an assault on salient features of an adolescent's own identity and affiliations, but it also represents an insult to family and kin. Although immigrant youth in Canada may report somewhat higher prevalence rates of this form of victimization, it appears that, regardless of how long an individual has lived in the country, youth who report this type of destructive peer interaction are at risk for maladaptation. Early identification of ethnic victimization is essential to ensure that youth who are victimized are supported and that healthy relationships are facilitated. 


\section{References}

Ashmore, R.D., Deaux, K., \& McLaughlin-Volpe, T. (2004). An organizing framework for collective identity: Articulation and significance of multidimensionality. Psychological Bulletin, 130, 80-114.

Besag, V.E. (1989). Bullies and victims in schools. Philadelphia, PA: Open University Press.

Craig, W.M., \& Harel, Y. (2004). Bullying, physical fighting, and victimization. In C. Currie, C. Roberts, A. Morgan, R. Smith, W. Settertobulte, O. Samdal, \& V. Barnekow Rasmussen (Eds.), Young people's health in context. Health behaviour in school-aged children (HBSC) study: International report from the 2001/2002 survey (Health Policy for Children and Adolescents, No.4, pp. 133-144). Copenhagen, Denmark: World Health Organization.

Craig, W.M., \& Pepler, D.J. (2003). Identifying and targeting risk for involvement in bullying and victimization. Canadian Journal of Psychiatry, 48, 577-582.

Fuligni, A.J., Witkow, M., \& Garcia, C. (2005). Ethnic identity and the academic adjustment of adolescents from Mexican, Chinese, and European backgrounds. Developmental Psychology, 41, 799-811.

Graham, S., \& Juvonen, J. (1998). Self-blame and peer victimization in middle school: An attributional analysis. Developmental Psychology, 34, 587-599.

Graham, S., \& Juvonen, J. (2002). Ethnicity, peer harassment, and adjustment, in middle school: An exploratory study. Journal of Early Adolescence, 22, 173-199.

Hamm, J. (2000). Do birds of a feather flock together? The variable bases for African American, Asian American, and European American adolescents' selection of similar friends. Developmental Psychology, 36, 209-219.

Hanish, L.D., \& Guerra, N.G. (2002). A longitudinal analysis of patterns of adjustment following peer victimization. Development and Psychopathology, 14, 69-89.

Hanish, L.D., \& Guerra, N.G. (2000). The roles of ethnicity and school context in predicting children's victimization by peers. American Journal of Community Psychology, 28, 201-223.

Hawker, D.S.J., \& Boulton, M.J. (2000). Twenty years' research on peer victimization and psychosocial maladjustment: A meta-analytic review of cross-sectional studies. Journal of Child Psychology and Psychiatry, 41, 441-455.

Juvonen, J., \& Graham, S. (Eds.). (2001). Peer harassment in school: The plight of the vulnerable and the victimized. New York: Guilford. 
Kochenderfer, B.J., \& Ladd, G.W. (1996). Peer victimization: Cause or consequence of school maladjustment. Child Development, 67, 1305-1317.

Olweus, D. (1989). Bully/victim questionnaire for students. Department of Psychology. University of Bergen.

Olweus, D. (1991). Bully/victim problems among school children: Some basic facts and efects of a school-based intervention program. In D. Pepler and K. Rubin (Eds.), The develop-ment and treatment of childhood aggression (pp. 411-448). Hillsdale, NJ: Erlbaum.

Operario, D., \& Fiske, S.T. (2001). Ethnic identity moderates perceptions of prejudice: Judgments of personal versus group discrimination and subtle versus blatant bias. Personality and Social Psychology Bulletin, 27, 550-561.

Oppendal, B., Røysamb, E., \& Heyerdahl, S. (2005). Ethnic group, acculturation, and psychiatric problems in young immigrants. Journal of Child Psychology, and Psychiatry, $46,646-\quad 660$.

Pepler, D., \& Craig, W. (2000). Making a difference in bullying. LaMarsh Report No. 60. Toronto: LaMarsh Centre for Research on Violence and Conflict Resolution, York University.

Pepler, D., \& Craig, W. (in press). Developmental and systemic perspectives on bullying. In K. Saito \& P. Smith (Eds.), Bullying in schools. Louisville, KY: Minerva Publishing.

Pepler, D.J., McKenney, K.S., \& Craig, W.M. (2006, March). Bullying: The risks for ethnic minority youth. In D. Strohmeier (Chair), Bullying and Victimization in Multicultural Schools: Identifying Risk Factors for Children of Immigration. Symposium conducted at the biennial meeting of the Society for Research on Adolescence, San Francisco, CA.

Nesdale, D., Durkin, K., Maass, A., \& Griffiths, J. (2004). Group status, out-group ethnicity and children's ethnic attitudes. Journal of Applied Developmental Psychology, 25, 237-251.

Nesdale, D., Maass, A., Griffiths, J., \& Durkin, K. (2003). Effects of in-group and out-group ethnicity on children's attitudes towards members of the in-group and out-group. British Journal of Developmental Psychology, 21, 177-192.

Rigby, K. (1998). The relationship between reported health and involvement in bully victim problems among male and female secondary school students. Journal of Health Psychology, 3, 465-476. 
Rigby, K., \& Slee, P.T. (1993). Dimensions of interpersonal relating among Australian school children and their implications for psychological well-being. Journal of Social Psychology, 133, 33-42.

Rumbaut, R.G. (1996). The crucible within: Ethnic identity, self-esteem, and segmented assimilation among children of immigrants. International Migration Review, 28, 749794.

Slonim-Nevo, V., Sharaga, Y., Mirsky, J., Petrovsky, V., \& Borodenko, M. (2006). Ethnicity versus migration: Two hypotheses about the psychosocial adjustment of immigrant adolescents. International Journal of Social Psychiatry, 52, 41-53.

Smith, P.K., \& Shu, S. (2000). What good schools can do about bullying: Findings from a survey in English schools after a decade of research and action. Childhood, 7, 193212.

Statistics Canada (2003). Canada's ethnocultural portrait: The changing mosaic. Retrieved June 5, 2006, from http://www.statcan.ca.

Stevens, G.W.J.M., Vollebergh, W.A.M., Pels, T.V.M., \& Crijnen, A.A.M. (2005a). Predicting externalizing problems in Moroccan immigrant adolescents in the Netherlands. Social Psychiatry and Psychiatric Epidemiology, 40, 571-579.

Stevens, G.W.J.M., Vollebergh, W.A.M., Pels, T.V.M., \& Crijnen, A.A.M. (2005b). Predicting internalizing problems in Moroccan immigrant adolescents in the Netherlands. Social Psychiatry and Psychiatric Epidemiology, 40, 1003-1011.

Strohmeier, D., Atria, M., \& Spiel, C. (2005, August). Bullying and victimization in multicultural school classes in Austria: Who is involved? Which reasons do victims give? In D. Strohmeier \& H. Fandrem (Chairs), Bullying and Victimization in multicultural schools: Towards an understanding of being immigrant in different European countries. Symposium conducted at the meeting of the XII European Conference on Developmental Psychology (ESDP), Tenerife, Spain.

Strohmeier, D., \& Spiel, c. (2003). Immigrant children in Austria: Aggressive behavior and friendship patterns in multicultural school classes. Journal of Applied School Psychology, 19, 99-116.

Verkuyten, M., \& Thijs, J. (2000). Leren (en) Waarderen: Discriminatie, zelfbeeld, relaties en leerrestaties in witte en zwarte basisscholen, Amsterdam: Thela Thesis.

Verkuyten, M., \& Thijs, J. (2002). Racist victimization among children in The Netherlands: The effect of ethnic group and school. Ethnic and Racial Studies, 25, 310-331. 
Williams, T., Connolly, J., Pepler, D., \& Craig, W. (2005). Peer victimization, social support, and psychosocial adjustment of sexual minority adolescents. Journal of Youth and Adolescence, 34, 471-482,

Yu, S.M., Huang, Z.H., Schwalberg, R.H., Overpeck, M., \& Kogan, M.D. (2003). Acculturation and the Health and Well-being of U.S. Immigrant Adolescents. Journal of Adolescent Health, 33, 479-488. 
Table 1.Mean Scores as a Function of Immigration Status For All Variables.

\begin{tabular}{lccc} 
& $0^{\text {th }}$ generation & $1^{\text {st }}$ generation & $2^{\text {nd }}$ generation \\
\hline General victimization & $.21(.60)$ & $.23(.60)$ & $.31(.70)$ \\
Ethnic victimization & $.22(.50)$ & $.28(.75)$ & $.15(.49)$ \\
Internalizing problems-Time 1 & $12.39(9.07)$ & $12.25(9.03)$ & $13.76(10.68)$ \\
Internalizing problems-Time 2 & $12.47(9.16)$ & $11.77(9.78)$ & $12.40(9.71)$ \\
Externalizing problems-Time 1 & $10.10(7.18)$ & $10.20(8.46)$ & $12.03(7.76)$ \\
Externalizing problems-Time 2 & $11.24(6.81)$ & $10.99(8.87)$ & $12.47(7.45)$
\end{tabular}

$* p<.05 . * * p<.01 . * * * p<.001$

Table 2.Analysis of Variance for General Victimization

\begin{tabular}{lcccc}
\hline \multicolumn{1}{c}{ Source } & $d f$ & $F$ & $\eta^{2}$ & $p$ \\
\hline Gender (S) & 1 & $5.91^{*}$ & .01 & .02 \\
Immigration Status (I) & 2 & 1.23 & .01 & .29 \\
$\mathrm{~S} \times \mathrm{I}$ & 2 & .22 & .001 & .80 \\
$S$ within-group error & 499 & $(.43)$ & & \\
\hline
\end{tabular}

Note. Values enclosed in parentheses represent mean square errors.

$* p<.05$. 
Table 3.Analysis of Variance for Ethnic Victimization

\begin{tabular}{lcccc}
\multicolumn{1}{c}{ Source } & $d f$ & $F$ & $\eta^{2}$ & $p$ \\
\hline Gender (S) & 1 & $7.19^{* *}$ & .01 & .01 \\
Immigration Status (I) & 2 & 2.53 & .01 & .08 \\
$\mathrm{~S} \times \mathrm{I}$ & 2 & .76 & .003 & .47 \\
$S$ within-group error & 499 & $(.31)$ & & \\
\hline
\end{tabular}

Note. Values enclosed in parentheses represent mean square errors.

$* p<.05 . * * p<.01$.

Table 4.Intercorrelations Among Victimization and Adjustment Variables Between Immigrant groups.

\begin{tabular}{lllllll}
\hline Variable & 1 & 2 & 3 & 4 & 5 & 6 \\
\hline & $0^{\text {th }}$ generation youth $(\mathrm{n}=107)$ & & \\
1. General victimization & -- &. & & & \\
2. Ethnic victimization & $.24^{*}$ & -- & & & \\
3. Internalizing problems-Time 1 & $.20^{*}$ & .08 & -- & & \\
4. Internalizing problems-Time 2 & $.24^{*}$ & .04 & $.67^{* *}$ & -- & & \\
5. Externalizing problems-Time 1 & $.22^{*}$ & .12 & $.63^{* *}$ & $.41^{* *}$ & -- & \\
6. Externalizing problems-Time 2 & $.20^{*}$ & .07 & $.40^{* *}$ & $.48^{* *}$ & $.68^{* *}$ & -- \\
\hline
\end{tabular}

$1^{\text {st }}$ generation youth $(\mathrm{n}=104)$

1. General victimization

2. Ethnic victimization .18

3. Internalizing problems-Time $1 \quad .09 \quad .10$

4. Internalizing problems-Time $2 \quad .01$

.12

$.67 * *$

5. Externalizing problems-Time $1 \quad .14$

$.21 *$

$.42 * *$

$26 * *$

6. Externalizing problems-Time $2 \quad .04$

$.34 * *$

.17

$.41 * * \quad .55 * *$

$2^{\text {nd }}$ generation youth $(\mathrm{n}=295)$

1. General victimization

2. Ethnic victimization $.23^{* *} \quad--$

3. Internalizing problems-Time $1 \quad .22 * * \quad .14 *$

4. Internalizing problems-Time $2 \quad .10$

.11

5. Externalizing problems-Time $1 \quad .08$

$.18^{* *} .56^{* *}$

$.35 * *$

6. Externalizing problems-Time $2 \quad .09$

.11

$.40 * *$

$.50 * *$

${ }^{*} p<.05$. ${ }^{* *} p<.01$. 
Table 5.Summary of Hierarchical Regression Analysis for Variables Predicting Internalizing Scores

\begin{tabular}{|c|c|c|}
\hline & Within Time & Over Time \\
\hline Variable & $\Delta R^{2}$ & $\Delta R^{2}$ \\
\hline
\end{tabular}

\section{Step 1}

Gender

Immigration status
$1^{\text {st }}$ generation vs. $2^{\text {nd }}$ generation -.06
$0^{\text {th }}$ generation vs. $2^{\text {nd }}$ generation -.01
$.06 * * *$

$.05 * * *$

Step 2

Gender

Immigration status
$1^{\text {st }}$ generation vs. $2^{\text {nd }}$ generation -.05
$-.01$
$0^{\text {th }}$ generation vs. $2^{\text {nd }}$ generation -.002
.03
General victimization
$.22 * *$
$.05^{* * *}$
$.14 * *$

$.02 * *$

Step 3

Gender

$.26^{* * *}$

$.26 * * *$

Immigration status

$\begin{array}{lll}1^{\text {st }} \text { generation vs. } 2^{\text {nd }} \text { generation } & -.06 & -.03 \\ 0^{\text {th }} \text { generation vs. } 2^{\text {nd }} \text { generation } & .002 & .03\end{array}$

General victimization

Ethnic victimization

$.10^{*}$

$.01 *$

$.11 *$

$.01 *$

${ }^{*} p<.05$. **p $<.01$. *** $p<.001$. 
Table 6.Summary of Hierarchical Regression Analysis for Variables Predicting Externalizing Scores

\begin{tabular}{|c|c|c|c|c|}
\hline \multirow[b]{2}{*}{ Variable } & \multicolumn{2}{|c|}{$\underline{\text { Within Time }}$} & \multicolumn{2}{|c|}{ Over Time } \\
\hline & $\beta$ & $\Delta R^{2}$ & $\beta$ & $\Delta R^{2}$ \\
\hline \multicolumn{5}{|l|}{ Step 1} \\
\hline Gender & $-.01 * * *$ & & .03 & \\
\hline \multicolumn{5}{|l|}{ Immigration status } \\
\hline $1^{\text {st }}$ generation vs. $2^{\text {nd }}$ generation & -.12 & & $-.11 *$ & \\
\hline $0^{\text {th }}$ generation vs. $2^{\text {nd }}$ generation & .01 & .01 & .04 & .01 \\
\hline \multicolumn{5}{|l|}{ Step 2} \\
\hline Gender & .01 & & .04 & \\
\hline \multicolumn{5}{|l|}{ Immigration status } \\
\hline $1^{\text {st }}$ generation vs. $2^{\text {nd }}$ generation & $-.11 *$ & & -.11 & \\
\hline $0^{\text {th }}$ generation vs. $2^{\text {nd }}$ generation & .01 & & .04 & \\
\hline General victimization & $.12 * *$ & $.01 *$ & $.10 *$ & $.01^{*}$ \\
\hline \multicolumn{5}{|l|}{ Step 3} \\
\hline Gender & .02 & & .06 & \\
\hline \multicolumn{5}{|l|}{ Immigration status } \\
\hline $1^{\text {st }}$ generation vs. $2^{\text {nd }}$ generation & $-.13 *$ & & $-.13 *$ & \\
\hline $0^{\text {th }}$ generation vs. $2^{\text {nd }}$ generation & .02 & & .05 & \\
\hline General victimization & .08 & & .06 & \\
\hline Ethnic victimization & $.16^{* * *}$ & $.02 * *$ & $.17 * * *$ & \\
\hline
\end{tabular}

$.03 * * *$

${ }^{*} p<.05 . * * p<.01 . * * * p<.001$.

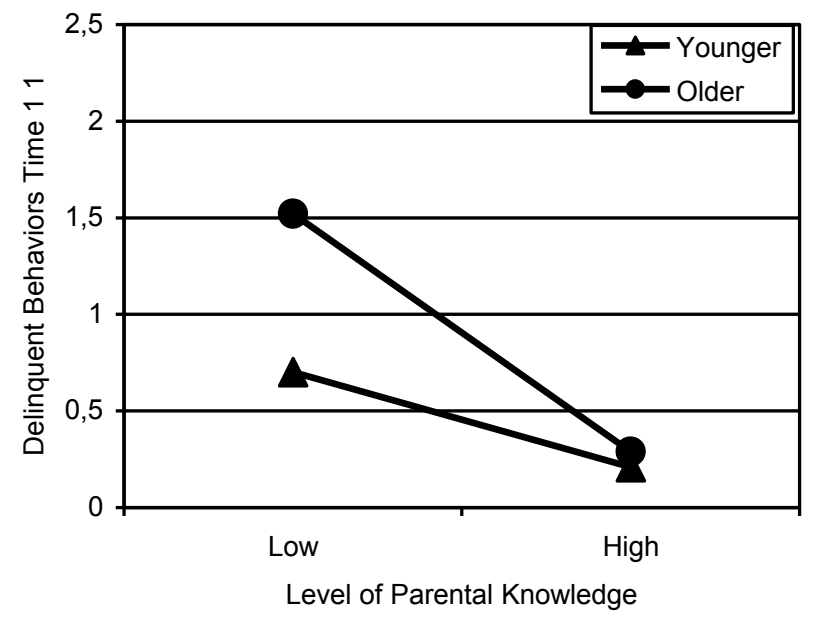


Figure 1. Percentage of participants who report at least one incident of victimization

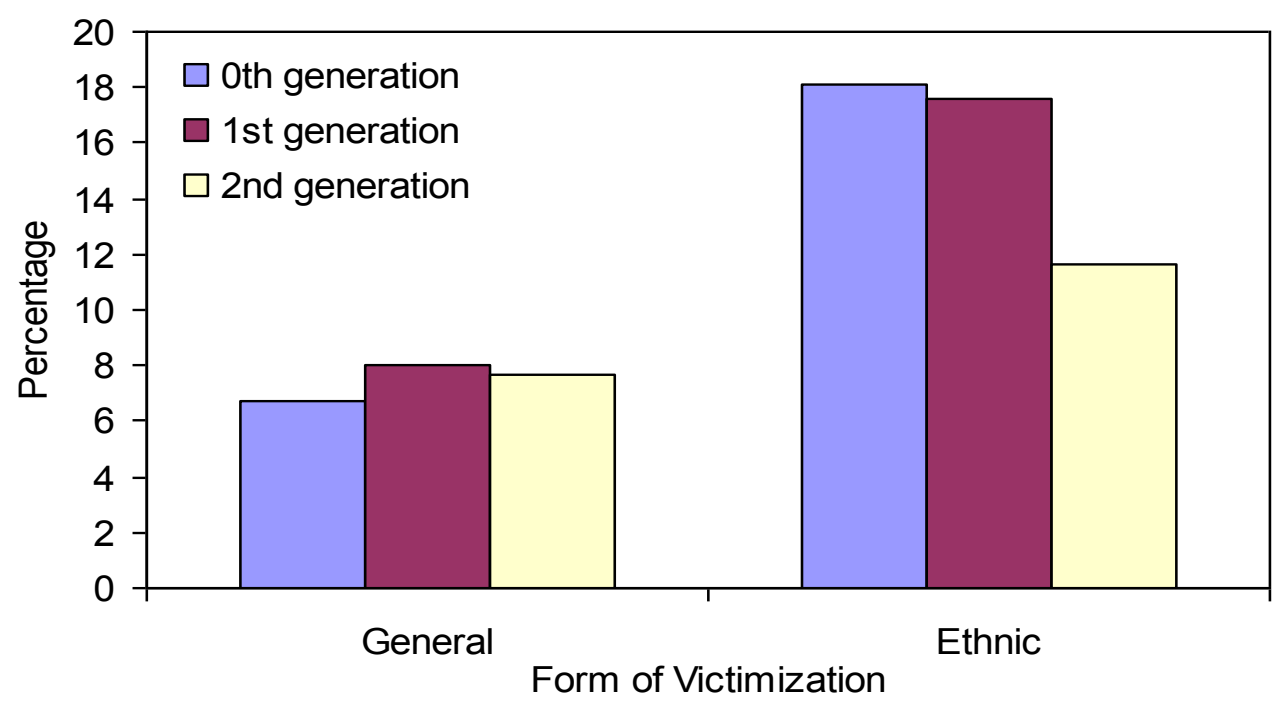

Figure 2. Mean differences in victimization experiences among immigrant groups.

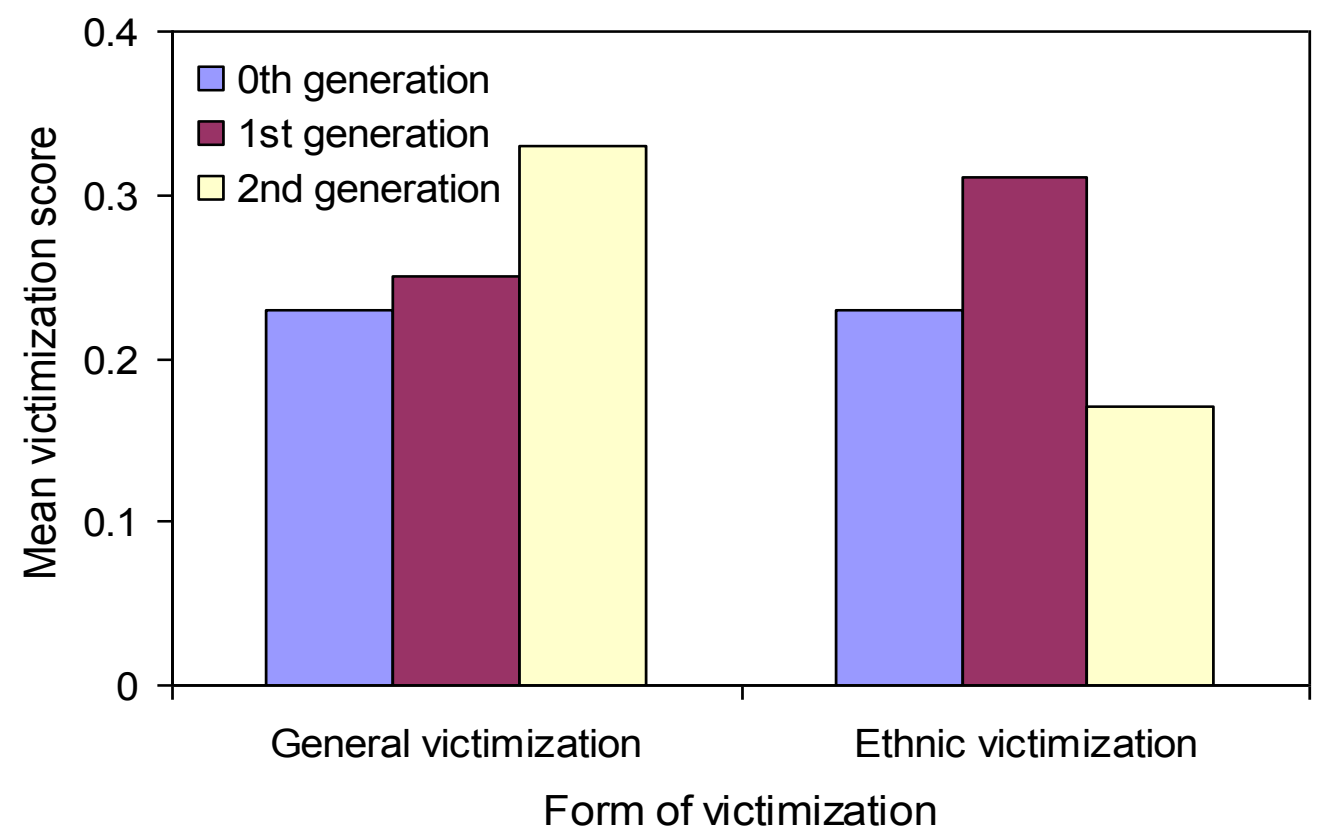

